$\begin{array}{ll}\text { Research Square } & \begin{array}{l}\text { Preprints are preliminary reports that have not undergone peer review. } \\ \text { They should not be considered conclusive, used to inform clinical practice, } \\ \text { or referenced by the media as validated information. }\end{array}\end{array}$

\title{
Simultaneous Detection of Velogenic Genotype XIII 2.2 Avian Avulavirus Type 1 (AAvV-1) From Spot-billed Pelican and Backyard Chicken: Implications to the Viral Maintenance and Spread
}

Deepthi Balam ( $\nabla$ drdeepthib@gmail.com)

NTR College of Veterinary Science https://orcid.org/0000-0002-2202-5634

D Ratnamma

Karnataka Veterinary Animal and Fisheries Sciences University

Shrikrishna Isloor

Karnataka Veterinary Animal and Fisheries Sciences University

Veeregowda BM

Karnataka Veterinary Animal and Fisheries Sciences University

M Himaja

Animal disease diagnostic lab, Visakhapatnam

Research Article

Keywords: Avian Avula virus-1, Pelecanus philippensis, Chicken, Transmission, Pathogenicity, India

Posted Date: June 30th, 2021

DOI: https://doi.org/10.21203/rs.3.rs-652737/v1

License: (c) (i) This work is licensed under a Creative Commons Attribution 4.0 International License. Read Full License 


\section{Abstract}

The present study demonstrates simultaneous isolation of genetically similar velogenic Avian Avula virus- 1 from an apparently healthy spot- billed pelican and a naturally infected backyard chicken in the adjacent vicinity. A total of fourty eight cloacal swab samples from migratory birds (Painted storks, $\mathrm{n}=32$ and Spot billed pelicans, $n=16$ ) at the Telineelapuram bird sanctuary in Andhra Pradesh, India and tissue samples of dead backyard chicken were collected. Two isolates were recovered, one each from a spot billed pelican (MIG-9) and a dead chicken (SKLM-1). The isolates were confirmed as velogenic based on mean death time, intra cerebral pathogenicity index and the putative fusion protein cleavage site $\left({ }^{113} \mathrm{R}-\mathrm{R}-\mathrm{K}-\mathrm{R}-\mathrm{F}^{117}\right)$. Phylogenetic analysis based on full- length fusion and attachment $(\mathrm{HN})$ proteins classified the isolates into genotype XIII, sub- genotype 2.2. Sequence analysis revealed that the pelican and chicken isolates were $100 \%$ identical. The study isolates demonstrated multiple amino acid substitutions at several critical domains of $\mathrm{F}$ and $\mathrm{HN}$ proteins when compared with the current vaccine strains. Pathogenic and transmission potential of the AAvV-1 isolates was evaluated in three- week old chicken and the isolates proved to be highly virulent to chicken. To the best of our knowledge, this is the first evidence for the role of spot-billed pelicans in the maintenance of virulent AAvV-1 and its transmission to chicken. This study further highlights the role of wild birds in AAvV-1 transmission and the need for enhanced biosecurity in commercial poultry operations.

\section{Introduction}

Newcastle Disease (ND) is a devastating infectious disease of poultry causing serious economic losses to the industry as well as farmers worldwide. ND is caused by Avian avulavirus type 1 (AAvV-1) of the genus Avian orthoavulavirus 1 (AOAV-1) within the subfamily Avulavirinae of the family Paramyxoviridae[1]. The disease is characterized by rapid onset of respiratory and nervous symptoms in susceptible species of birds including chickens, pigeon, and turkeys. Wide range of domestic and wild birds are susceptible to AAvV- 1 infections worldwide. Birds of 241 species from 27 orders are reported to be susceptible to ND [2]. Wild birds act as natural reservoirs of AAvV-1, with frequent viral transmission to domestic birds.

AAvV-1 is an enveloped virus with helical symmetry, and carry negative sense single-stranded RNA genome. The genome has been reported to possess six genes in the order of nucleoprotein $(\mathrm{N})$, phosphoprotein $(\mathrm{P})$, matrix $(\mathrm{M})$, fusion $(\mathrm{F})$, hemagglutinin neuraminidase $(\mathrm{HN})$ and large polymerase $(\mathrm{L})$ and translated into eight proteins. Of the eight proteins encoded by the genome, F and HN proteins are the important protective and neutralizing antigens of NDV. Fusion protein encompassing fusion protein cleavage site (FPCS) is the most important virulence factor [3]. Further, based on the full - length fusion gene sequences, AAvV-1 has been classified into two major classes, I and II. All the avirulent isolates were classified under Class I, which includes a single genotype with three subgenotypes. Class II contains most of the virulent viruses circulating worldwide, classified into atleast 21 genotypes with multiple subgenotypes [4] and this diversity continues to increase as the surveillance studies improves.

Spill over of viruses from domestic poultry into wild birds and vice versa has been the recent area of research. Avian Influenza studies highlighted the role of reservoir host in perpetuation of a pathogen and subsequent spill over into domesticated population resulting in severe form of outbreaks [5] which also holds true with ND [6]. Virulent AAvV-1 of several genotypes are often identified in wild birds like water fowls and white storks, and the latter have been speculated to play a role in the spread of the virus [7]. However, it is suggested that most of the wild bird isolations are a result of spill over of virus from infected poultry [8] and vice- versa. Other than pigeons, doves, and double-crested cormorants, most wild birds are not known to harbor virulent NDV strains. Role of the spotbilled pelican or grey pelican (Pelecanus philippensis) and painted storks (Mycteria leucocephala) that breed only in peninsular India, Sri Lanka and in Cambodia, in the epidemiology of AAvV-1 is unknown. It is quintessential to understand the potential risks of transmission of chicken- and wild bird-origin AAvV-1 in poultry in outbreak response and control of ND.

Here we report isolation of virulent AAvV-1 from apparently healthy spot-billed pelican at the Telineelapuram bird sanctuary in Andhra Pradesh and dead backyard poultry in the adjacent area. Pelican- origin isolate was evaluated for its pathogenicity and transmissibility in naive chicken. Considering all the previously mentioned facts and the preliminary evidence of the probable spill over of AAvV-1 between wild migratory birds and domesticated poultry, the present study may act as potential proof of this assertion.

\section{Materials And Methods}

\section{Sampling procedures}

Telineelapuram bird reserve, a home to painted storks and spot billed pelicans located in Srikakulam district of Andhra Pradesh, India is considered as a crucial stopover for birds migrating from Siberia to Peninsular India annually. Painted storks, grey pelicans and spot billed pelicans migrate every year from Siberia during the month of October and stay here till March. Coastal belt including Srikakulam district is an important poultry hub of Andhra Pradesh and is endemic to various poultry diseases including Newcastle disease. A total of fourty eight cloacal swab samples (Painted storks, $n=32$ and Spot billed pelicans, $n=16$ ) were collected during the year 2018 , from sick birds that were in a non- flying stage in the enclosures under the supervision of forest department following all the guidelines and regulations. During the same period, tissue samples including caecal tonsils, spleen, trachea, lungs, kidneys were collected during necropsy of backyard chicken $(n=15)$ suspected for ND at Animal Disease Diagnostic Lab (ADDL), Srikakulam. Cloacal swabs and tissue samples were collected in phosphate buffered saline (PBS) supplemented with an antibiotic mixture (2000 unit/ ml Penicillin G, 200mg/ml Streptomycin and 4mg/ml Amphotericin $\mathrm{B}$ ) and frozen at $-20^{\circ} \mathrm{C}$ until used in virus isolation and processed as per standard procedures [3].

\section{Ethical statement}

All the animal experimental protocols performed in the study are approved by Institutional animal ethics committee of NTR college of veterinary science, Gannavaram, Andhra Pradesh (Approval number: 5/IAEC/NTRCVSC/2018). 


\section{Isolation of AAvV-1 in ECE's}

Cloacal swabs and tissues were processed as $10 \%$ homogenates in $500 \mu \mathrm{l}$ of PBS supplemented with antibiotics. Swab fluids and tissue homogenates were clarified by centrifugation at $4^{\circ} \mathrm{C}$ for $8 \mathrm{~min}$ at $2500 \mathrm{rpm}$, and the supernatant was used for inoculation into 9-day old embryonated chicken eggs (ECE) through allantoic route following standard procedures [3]. The inoculated eggs were incubated at $37^{\circ} \mathrm{C}$, checked for mortality every $12 \mathrm{~h}$ until the embryos died or for a maximum period of $120 \mathrm{~h}$, whichever was earlier. The dead embryos were chilled at $4^{\circ} \mathrm{C}$ overnight for collection of amnioallantoic fluid (AAF). Each sample was passaged blindly thrice before considering it as negative. Presence of AAvV-1 was confirmed by Hemagglutination activity (HA) as well as hemagglutination inhibition ( $\mathrm{HI})$ test. The AAF was also used in RT-PCR to confirm the presence of AAvV-1. Lasota, a lentogenic vaccine strain (IVPM, Ranipet, India) was used as antigen $\left(10^{5} \mathrm{EID}_{50}\right.$ per vial) for preparation of hyper-immune serum and as a positive control in virus isolation and RT-PCR.

\section{Detection of AAvV-1 by RT- PCR}

The AAvV-1 isolates positive by $\mathrm{HI}$ test were further confirmed by reverse transcription PCR. The AAF harvested during the third passage was used for RNA isolation employing TRIsoln reagent (Genei, India) following manufacturer's instructions. First strand cDNA was synthesized using random primer and iScript ${ }^{\mathrm{TM}}$ CDNA synthesis kit (Biorad, USA). The isolates were confirmed as AAvV-1 by Polymerase chain reaction (PCR) using primers targetting fusion protein cleavage site (FPCS) [9]. Full- length F gene (1662 bp) of the isolates was amplified using consensus primers described previously [10]. Full- length HN gene (1716 bp) of the isolates was amplified using the following primers designed for this study; HNF-5'- AGA ACG GTC AAA GGA GCC AC- 3' and HNR-5'- GGT GCA ACA CCT TCC TTC CA- 3'. The primers generate an expected amplicon size of 1860 bp (nt 6333-8192) fragment spanning the actual HN gene region from nt 6418- $8133 \mathrm{bp}$. Another set of internal primers were designed to facilitate full gene sequencing: INT-F- 5'-TCAATACTTGGCACTCGGTG-3' and INT-R-5'TTAGGTGGAACAGTCAGCAC-3'. Briefly, a total of $25 \mu \mathrm{l}$ reaction mixture is prepared using $2 \mu \mathrm{l}$ of cDNA, $12.5 \mu \mathrm{l}$ of $2 \mathrm{X}$ Phusion high fidelity master mix with HF buffer, $0.75 \mathrm{ul}$ of DMSO, $1.25 \mu \mathrm{l}$ primer HNF, $1.25 \mu \mathrm{l}$ primer HNR and $7.25 \mu \mathrm{l}$ nuclease free water. The reaction conditions were as follows: One initial PCR activation cycle at $98^{\circ} \mathrm{C} / 3 \mathrm{~min}$ followed by 35 three-step cycles of $98^{\circ} \mathrm{C} / 10 \mathrm{~s}, 65^{\circ} \mathrm{C} / 30 \mathrm{~s}$ and $72^{\circ} \mathrm{C} / 2 \mathrm{~min}$; then $72^{\circ} \mathrm{C} / 10 \mathrm{~min}$. The amplified $\mathrm{PCR}$ products were analysed using $1 \%$ agarose gel containing ethidium bromide and were visualized under UV illumination.

\section{Sequencing and phylogenetic analysis based on full- length fusion and $\mathrm{HN}$ genes}

The amplified PCR products were sequenced by Sanger sequencing with the help of commercial sequencing centre (Barcode Biosciences, India). The PCR products were purified using QIAquick Gel Extraction Kit (Qiagen, Germany). F and HN gene products of the pelican and chicken isolates were sequenced bidirectionally with both sense and antisense primers that were used in the PCR amplification. The sequencing was performed utilizing BigDye terminator v3.1 cycle sequencing kit in an ABI 3730 genetic analyser (Applied Biosystems Foster City, California, USA).

The F and HN gene sequence data of both the isolates were subjected to blast analysis with the help of NCBI BLAST tool (https:// blast.ncbi.nlm.nih.gov/Blast.cgi) and compared with the Avian Avula virus type 1 sequences available in GenBank. Multiple alignment of the coding regions of each of the two genes were performed using the clustalW algorithm in MEGAX [11]. Phylogenetic trees were inferred to localize the pelican and chicken isolates amongst representative class II reference strains according to the maximum-likelihood method based on the general time-reversible model as implemented in MEGA X software. Initial tree(s) for the heuristic search were obtained automatically by applying Neighbor-Join and BioNJ algorithms to a matrix of pairwise distances estimated using the Maximum composite likelihood (MCL) approach, and then selecting the topology with superior log likelihood value. The maximum likelihood method based on the General Time Reversible (GTR) model with a discrete gamma distribution (five categories [+G]) was utilised for all the trees. The trees were generated by using the neighbour-joining algorithm, and alignments were bootstrapped 1000 times. All positions containing gaps and missing data were eliminated. The evolutionary relationship between the two isolates and 41 viruses belonging to the 21 genotypes of class II Avian Avula viruses were estimated by calculating the number of base differences per site from averaging over all sequence pairs between groups using MEGAX [11]. Details of the accession numbers used for phylogenetic analysis were mentioned in the supplementary material.

\section{Biological characterization of AAvV-1 isolates}

The two isolates obtained in the study were biologically characterized for their pathogenicity employing mean death time (MDT) in nine- day old ECE's and intracerebral pathogenicity index (ICPI) in day- old chicks as per standard procedures [3]. AAvV-1 pathotypes were classified based on MDT, as follows: velogenic, if death occurs within $60 \mathrm{~h}$; mesogenic, 60-90 h; and lentogenic, more than $90 \mathrm{~h}$. Based on ICPI, velogenic viruses give ICPI indices that approach the maximum score of 2.0 , whereas lentogenic strains give values close to 0.0 .

\section{Pathogenicity assay in three- week old chicken}

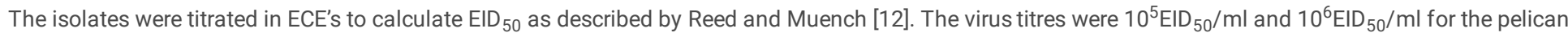
and chicken isolates repectively. A total number of thirty six, three- week old broiler chicks were obtained from M/s Sreenivasa hatcheries, Vijayawada, India. The chicks were confirmed to be free of AAvV-1 antibodies by $\mathrm{HI}$ before the start of the experiment. All the chicks were housed in an isolated, well- ventilated room and provided with balanced ration and water ad libitum throughout the experiment. All biosecurity measures were taken care off. Of the thirty six birds, thirty were split into 3 groups viz., control group $(n=10)$, pelican isolate $(n=10)$ and chicken isolate $(n=10)$. At day0, chicks of both groups were inoculated with $0.5 \mathrm{ml}\left(10^{3} \mathrm{EID}_{50} / 0.5 \mathrm{ml}\right)$ of the respective AAvV-1 isolate. Control group was placed in separate facility and inoculated with $0.5 \mathrm{ml}$ PBS. Virus transmission was assessed by placing three naïve, uninfected chicks in a separate cage next to the groups infected with AAvV-1 isolates. Infected and sentinel birds were observed regularly for clinical signs and mortality.

\section{Results}


Backyard poultry flock from which the samples were collected was not vaccinated against ND. Birds in the affected flock showed anorexia, depression, prostration, greenish diarrhea 3 days before the onset of mortality. The necropsy findings observed in few birds were pin point haemorrhages in the proventricular glands, segmental congestion in the intestinal mucosa and necrotic lesions in the caecal tonsils.

\section{Isolation and characterization of AAvV-1}

Tissue homogenates of dead backyard poultry resulted in peri- occipital haemorrhages and diffuse congestion in the inoculated dead embryos during the first passage. Of the forty eight cloacal swabs collected from the migratory birds, one sample from spot- billed pelican showed similar changes in the inoculated embryos during second passage. Amnio allantoic fluids (AAF) were collected 48h post inoculation and presence of AAvV-1 was confirmed by HA and HI assays employing polyclonal chicken antiserum raised against LaSota. AAvV-1 isolates confirmed by HI were further confirmed by RT-PCR targeting partial fusion gene encompassing FPCS. Both the isolates were classified as velogenic based on the MDT and ICPI values (Table 1).

The two isolates were plaque purified in confluent monolayers of chicken embryo fibroblast (CEF) cultures, stored at $-80^{\circ} \mathrm{C}$ and are hereby referred as AAvV/Chicken/SKLM-1/2018 (SKLM-1) and AAvV/Pelican/ Telineelapuram/2018 (MIG-9).

\section{Genotype analysis}

The amplified F and HN gene sequences of SKLM-1 and MIG-9 isolates were submitted to GenBank and are available under accession numbers: MT036311(SKLM-1/F); MZ270546 (SKLM-1/HN); MN901912 (MIG-9/F); MT909566 (MIG-9/HN).

The SKLM-1 and MIG-9 isolates were 100\% identical to each other. The topology of the phylogenetic trees was found to be similar when constructed either based on full- length fusion or HN genes (Figure 1\&2). Both the isolates were classified as members of genotype XIII of class II. Further analysis employing reference strains of sub- genotypes of genotype XIII $(1.1,1.2,2.1,2.2)$ showed that the isolates clustered closely with viruses belonging to sub- genotype XIII 2.2 isolates. Based on the fusion gene sequences, these isolates are closely related and have $99.2 \%$ identity with Avian Avula virus- 1 isolate $410 / 16 \mathrm{~A}$ (GenBank ID MF422129), 98.3\% identity with Avian Avula virus-1 isolate 96-15 (GenBank ID MF422125) and 97.8\% with AAVV isolate D162 (GenBank ID KX242342), which are all placed under the same subgenotype. Further, isolates like NDV strain Nagpur (GenBank ID KP089979), NDV/16/GODHRA/03/2013 (GenBank ID KM056344), NDV40/SARSA/04/2013 (GenBank ID KM056348), NDV/NAGPUR/04/11 (GenBank ID KX372708) are comparatively less identical with a divergence value of more than $5 \%$ although they were also included in the same genotype XIII 2.2. Based on HN gene sequences, AAvV/Pelican/ Telineelapuram/2018 isolate have $99.7 \%$ identity with Avian Avula virus- 1 isolate 410/16A (GenBank ID MF422129) and AAvV/Chicken/SKLM-1/2018 have 98.43\% identity with Avian Avula virus-1 isolate 96-15 (GenBank ID MF422125).

The deduced amino acid sequence of the fusion protein of both the isolates showed only a divergence of $0.8 \%$ with sub- genotype XIII 2.2 isolates, while the divergence with current vaccine strains ranged from $10-12.9 \%$. The deduced amino acid sequence of the HN protein showed a divergence of $0.3-1.57 \%$ with sub- genotype XIII 2.2 isolates and $11.3-14.5 \%$ with current vaccine strains.

\section{Analysis of fusion gene sequences}

Fusion genes of the two isolates were found to have a cds of 1662 nucleotides coding for 553 amino acids. Amino acid sequence at the FPCS cleavage site motif ${ }^{112} \mathrm{R}-\mathrm{R}-\mathrm{R}-\mathrm{K}-\mathrm{R}-\mathrm{F}^{117}$ has more than two pairs of basic amino acids and a Phenylalanine in the $\mathrm{N}$ terminus of the F1 protein (Table 1 ) typical for velogenic isolates. Table 2 shows the amino acid substitutions within the fusion peptide, heptad repeat regions (HRa, HRb, HRc and HRd) and transmembrane domains of the study isolates in comparision to the vaccine strains. Several amino acid substitutions were observed in these domains which are also noted in the reference strains of genotype XIII sub- genotype 2.2. Of the eight transmembrane domains in the fusion protein, six domains located at positions $15-25,118$ $131,120-128,266-269,429-432$ and 499-525 were unaltered, while several substitutions were noted in the domains, 14-27 and 501- 523. Six potential N-

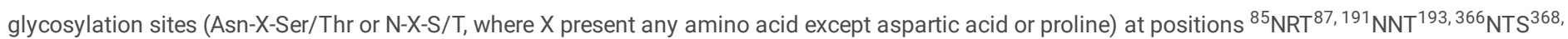
${ }^{447} \mathrm{NIS}^{449,}{ }^{471} \mathrm{NNS}^{473}$ and ${ }^{541} \mathrm{NNT}^{543}$ were unaltered in both the study isolates.

Amino acid substitutions within the hypervariable region and neutralizing epitopes of the isolates under study were compared with the vaccine strains (Table 3). Several unique substitutions were observed in the hypervariable region of the study isolates (R4K, A11I, M13L, M14G, T16I, I17T, A20M, V22I, P28L, A29T and L69I). M14G substitution is unique to the present isolates and is not identified even in the reference strains of genotype XIII sub- genotype 2.2 . Interestingly, hypervariable region of the study isolates were similar to Mukteshwar strain at amino acid positions 8,9,13,28,29 and 31 and to other vaccine strains at positions viz., 10, 25, 26, 27 and 30 . Neutralizing epitope sequences critical for structure and function of the fusion protein were similar to that of the vaccine strains.

\section{Analysis of $\mathrm{HN}$ gene sequences}

$\mathrm{HN}$ genes of the two isolates were found to have a cds of 1716 nucleotides coding for 571 amino acids. Three transmembrane domains at positions $24-47$, 25-45 and 557-563, a sialic acid binding site at position 234-239 and 13 Cystine (C) residues at positions 123, 172, 186, 196, 238, 247, 251, 344, 455, 461, 465, 531 and 542 were recognised in the HN proteins of either of the isolates. The Cysteine (C) residue at position 123 was present in R2B and Mukteshwar vaccine strains also, while it has been replaced by Tryptophan (W) in LaSota, Komarov and B1.

The $\mathrm{HN}$ proteins of the isolates were also found to have six glycosylation sites at positions $119,341,433,481,508$ and 538 . As compared to the vaccine strains, the study isolates have amino acid substitutions at positions G75S, N77G, V81I and I84V in heptad repeat region A domain and T101S and T102I 
substitutions in heptad repeat region B domain. Five neutralizing epitopes have been recognised in the HN protein of which, two epitopes viz., site 23 (193201) and site 1 and 14 (345-355) remained unaltered, while three epitopes viz., site 12 (494), site 2 and 12 (513-521) and site 2 (569) presented numerous substitutions (Table 4). Three amino acids at positions, 401E, 416R and 526Y characterized by functional triarginyl cluster considered essential for receptor binding and neuraminidase activity are conserved in the study isolates. HN protein motifs responsible for hemagglutinating activity, viz., ${ }^{234} \mathrm{NRKSCSV/I/L}{ }^{240}$, ${ }^{314} \mathrm{FPVYGGL} / \mathrm{V} / \mathrm{M}^{320}$ and ${ }^{399} \mathrm{GAEGRIL} / \mathrm{V} / \mathrm{I}^{405}$ remained unaltered in the study isolates.

\section{Pathogenicity assay in three- week old chicken}

Infection of three- week old chicken with the SKLM-1 and MIG-9 AAvV-1 isolates resulted in virulent ND with 100\% mortality. Clinical signs, gross and histopathological lesions induced by either of the isolates appeared similar and indicated that they caused systemic infection in chicks and replicated quickly in multiple tissues. Birds inoculated with either of the isolates, had evident clinical disease (depression, reluctancy to move, open mouthed breathing, mild conjunctivitis, ruffled feathers and greenish diarrhoea) at $2 \mathrm{dpi}$ which became more severe until death at 4 or $5 \mathrm{dpi}$. Also, neurological signs like ataxia, twitching, head tremors were observed hours before death. Birds exhibiting severe clinical signs were euthanised to perform necropsy. Gross lesions were found widespread throughout different tissues. Most frequent necropsy findings include hemorrhages in the proventriculus and caecal tonsils, swollen kidneys, tracheal hemorrhages and splenomegaly associated with mottling (Fig.3). The sentinel birds also started exhibiting similar clinical signs as the directly inoculated birds 5 days post exposure progressing to severe clinical signs by 7 days post exposure. Hundred percent mortality was observed in all the infected and sentinel birds. Control birds appeared clinically normal throughout the observation period.

Histological lesions were analysed in the tissues of infected, sentinel and control birds. No major differences were noticed in the birds infected with either of the viruses and in the sentinel birds. In spleen, lesions varied from vacoular changes to necrosis of the lymphoid tissue in the white pulp characterized by lymphocytolysis and lymphoid depletion. Heart revealed pericarditis and myocarditis characterized by degeneration of myocardium, infiltration of heterophils, fibrin, fibroblasts and mononuclear cells in the pericardium and myocardium. In the small intestines, lesions varied from catarrhal enteritis characterized by severe goblet cell hyperplasia to fusion, necrosis of villi and desquamation of epithelium into lumen. Lesions observed in the trachea during acute phase of respiratory disease were haemorrhages and vacoular changes in the tracheal mucosa, syncytia formation and denudation of tracheal epithelium. Lungs revealed severe congestion and consolidation of parenchyma, denudation and exudation of bronchiolar epithelium. In the kidneys, lesions included nephrosis characterized by degeneration to severe tubular necrosis and interstitial nephritis (Fig.4). No specific lesions were observed in the control group.

\section{Discussion}

Southeast Asia not only hosts the largest population of commercial and backyard poultry in the world [13] but also recognized as a unique biodiversity hotspot with one of the richest and diverse avifauna. Coastal wetlands of southeast Asia represent major wintering and staging sites for millions of water bird species that migrate from Siberia, Russia, Germany and Australia. The long coastal line and rivers in India also attracts several species of migratory birds which presents a unique opportunity to study mechanisms of viral maintenance and spread in this region. However, limited information is available regarding the potential role of these avian species in the dessimination of viruses. Monitoring of non- poultry avian species for infectious agents such as AAvV- 1 in their natural habitats and in areas that pose a risk of transmission between domestic poultry and wild birds will increase the knowledge of epidemiology, ecology and genetic relationships of such viruses. Hence, wild bird sanctuary located at Telineelapuram in Andhra Pradesh state was selected for this study and samples were collected from migratory birds viz., painted storks and spot- billed pelicans. This sanctuary had encroached into the human habitations and there is a fair chance for spillover and exchange of pathogens between the migratory birds and backyard poultry.

In the present study, two AAvV-1 isolates recovered from apparently healthy spot- billed pelican (MIG-9) and a dead backyard chicken (SKLM-1) were genotypically and pathotypically characterized. Chicken- origin AAvV-1 could be isolated during first passage, while the pelican- origin AAvV-1 isolate was recovered during second passage. Infective dose of AAvV-1 for a chicken ranges from $10^{3.0}$ [14] to $10^{4.0}$ EID $_{50}$ [15]. Virus load harboured by the asymptomatic pelicans might be very low thus necessitating repeated passages in embryonated chicken eggs for isolation of AAvV-1. Prediction of virulence based on the invivo pathogenicity assays complimented with FPCS motif helps in determining the pathotype of the isolate. Chicken- and pelican- origin isolates have MDT values $<50 \mathrm{~h}$, ICPI index more than 1.8 and FPCS motif with polybasic amino acids, indicating that the isolates belong to velogenic pathotype. ICPI is the generally accepted method to measure the virulence of AAvV-1strains because of its high accuracy and sensitivity [3]. Few authors even reported incongruencies between FPCS and invivo pathogenicity test [16,17].

Phylogenetic analysis based on the full- length sequences of fusion and $\mathrm{HN}$ genes indicated a close genetic relationship between the chicken- and pelican origin AAvV-1 and grouped the isolates under genotype XIII sub- genotype 2.2. The present isolates are more closely related to Avian Avula virus-1 isolate 410/16A (GenBank ID MF422129) and Avian Avula virus-1 isolate 96-15 (GenBank ID MF422125) based on full- length fusion and HN gene sequences which were also isolated from different parts of Andhra Pradesh, India. Phylogenetically, genotype II, IV, VII and XIII strains are circulating in Southeast Asia [18]. Several isolations of genotype XIII viruses were previously reported from different countries like India, Srilanka, Pakistan, Iran, Tanzania, Russia mostly from chicken $[10,19,20]$. Previous reports suggest isolation of velogenic AAvV-1 of subgenotype XIII 2.2 in commercial chicken flocks [10, 21] and an infected emu flock [22] in different parts of India. Several authors described isolation of AAvV-1 from variety of wild bird species including great white pelicans (Pelecanus onocrotalus) and highlighted their role as reservoir host for AAvV-1 [23, 24]. However, this study is the first of its kind reporting simultaneous isolation of a velogenic AAvV-1 of subgenotype XIII 2.2 from a spot- billed pelican and backyard chicken from India. Among the genotype XIII 2.2 Indian isolates, a variety of FPCS motifs were identified and this provides additional grounds for continued evolution of genotype XIII viruses in the country [25]. FPCS motif of the present

isolates viz., ${ }^{113}$ RRKR $\downarrow F^{117}$ resembles to that of genotype VIf AAvV-1 isolates responsible for the third ND panzootic [26] and this gives strength to the debate that the genotype XIII viruses might have re-emerged consequent to repeated passages in different bird species crossing geographical barriers, thereby transmitting the virus to the domestic poultry population, resulting in massive outbreaks. 
The deduced amino acid sequences of full- length $\mathrm{F}$ and HN proteins of the study isolates showed a divergence ranging from $10-12.9 \%$ and $11.3-14.5 \%$ with currently used vaccine strains LaSota, Komarov, R2B, B1 and Mukteshwar. Reports from several other studies were in agreement with the present findings [27, $28,10]$. Though the neutralizing epitopes in fusion protein are quite similar to that of the vaccine strains, several amino acid substitutions were noticed in the fusion peptide, hypervariable region, heptad repeat regions and transmembrane domains. In addition, amino acid substitutions were also identified in the antigenic sites of HN protein. Heptad repeat motifs in fusion and HN proteins interact with each other and are critical for fusion activity. Mutations in these domains have profound influence on virulence and pathogenicity of the isolates [29]. Mutations within the antigenic sites of HN protein may result in failure of antibody recognition capability. Hence, the chicken- and pelican- origin isolates may be considered as new immune- response escaping antigenic variants involved in ND outbreaks despite the flocks being vaccinated regularly. Mukteshwar strain is observed to have comparatively more similarity with the isolates under study than the other vaccine strains based on the phylogenetic studies. High genetic dissimilarity between vaccine strains and the circulating strains of AAvV-1 highlights the need to revamp the existing vaccination strategies.

The chicken- and pelican- origin AAvV-1 isolates were also characterized for their ability to induce infection in three- week old chicks and transmit to naive chicken. Either of the isolates caused $100 \%$ mortality in both the infected and sentinel birds with clinical signs, gross lesions and histopathological changes typical to virulent ND. This finding clearly demonstrates that chicken- origin and non chicken- origin AAvV-1 isolates could infect chicken in a similar manner. In agreement to the present findings, $100 \%$ mortality was recorded in chicken experimentally infected with peafowl- origin isolate [30]. In contrast, Ferreira et al. [31] reported that the pigeon and cormorant lineage viruses required a high challenge dose to infect chickens and did not transmit efficiently to contact birds, even when a high infectious dose was used. It is proven that pathogenicity also depends on host adaptability, as, a goose- origin isolate was found to be more pathogenic to geese than a chicken- origin isolate of the same genotype [32].

Spot- billed pelicans from which the isolate obtained was apparently healthy indicating that these birds may act as asymptomatic carriers of the virulent AAvV-1, and spread the virus during their seasonal patterns of migration. Most poultry around the wild bird sanctuary were raised in a free- range style and were never vaccinated against ND. Pelican- and chicken- origin isolates were $100 \%$ identical suggesting interspecies transmission of AAvV's. Migratory wild birds have shown to transmit AAvVs to free- range poultry through the contamination of water and feed [33]. Several studies reported accidental spillover of virus from poultry outbreaks to other bird species [34, 35, 36, 37]. It has been suggested that the AAvVs that spill-over from wild/feral birds or other species into poultry continue to evolve as they are rapidly passaged in chickens [36]. Hence, wildlife- poultry interface is shown to present a major risk factor to the poultry industry and highlights the need for enhanced biosecurity in commercial poultry operations.

\section{Conclusion}

To our knowledge, this is the first report on simultaneous detection of velogenic AAvV-1 from an asymptomatic spot- billed pelican and a dead backyard chicken in India. Based on phylogenetic analysis, the isolates were grouped into genotype XIII 2.2. Analysis of the deduced amino acid sequences of Fusion and HN proteins revealed several substitutions in critical domains essential for virulence of the virus. In addition, the AAvV- 1 isolates of the present study were highly divergent from the current vaccine strains. Hence, future studies need to be directed towards evolving novel vaccination regimes together with regular surveillance of migratory birds, aquatic water fowls and the domestic poultry to understand the dynamics and evolution of new AAvVs.

\section{Declarations}

\section{Acknowledgements}

The authors thank Sri Venkateswara Veterinary University (SVVU), Tirupati, India for funding the research and Department of Veterinary Microbiology, NTR College of Veterinary college, Gannavaram, AP, India for providing necessary facilities to carry out the research.

\section{Funding}

This work is supported by the funding received from Sri Venkateswara Veterinary University, Tirupati, India.

\section{Conflict of interest}

The authors state that there is no conflict of interest among them.

\section{Data availability statement}

The main data supporting this study are provided in the results section of this paper. The others data are provided as supplementary information accompanying this paper.

\section{Code availability}

Not applicable

\section{Authors contribution}

DB and RPRN conceived and designed the study. DB and HM collected samples from the wild bird sanctuary, Telineelapuram. RD contributed reagents to conduct experiments. DB performed experiments, analysed data and wrote the manuscript. RPRN, RD, VBM and SI edited the manuscript. All authors read and approved the manuscript. 


\section{Ethics approval}

All the experiments carried out in embryonated chicken eggs, day- old chicks and three- week old chicks were performed duly following the 'Guide for the Care and Use of Laboratory Animals' that was approved by Institutional Animal Ethics Committee, NTR College of Veterinary college, Gannavaram, AP, India.

\section{Consent to participate}

Not applicable

\section{Consent for publication}

Not applicable

\section{References}

1. Taxonomy IV. Release (2019) International committee on taxonomy of viruses.v/msw054.

2. Kaleta EF and Baldauf C (1988) Newcastle disease in free-living and pet birds. In: Newcastle disease, Springer, Boston, MA. pp 197-246.

3. OIE Manual of diagnostic tests and vaccines for terrestrial animals: mammals, birds and bees (2012). Newcastle disease. Biological Standards Commission. World Organisation for Animal Health, Paris, France. 555-574.

4. Dimitrov KM, Abolnik C, Afonso CL, Albina E, Bahl J, Berg M, Briand FX, Brown IH, Choi KS, Chvala I \& Diel D.G (2019) Updated unified phylogenetic classification system and revised nomenclature for Newcastle disease virus. Infection, Genetics and Evolution, 74:103917.

5. Swayne DE, Spackman E and Pantin-Jackwood M (2014) Success factors for avian influenza vaccine use in poultry and potential impact at the wild bird-agricultural interface. Eco Health, 11, 94-108.

6. Ayala AJ, Dimitrov KM, Becker CR, Goraichuk IV, Arns CW, Bolotin VI, Ferreira HL, Gerilovych AP, Goujgoulova GV, Martini MC and Muzyka DV (2016) Presence of vaccine-derived Newcastle disease viruses in wild birds, PloS one, 11(9), p.e0162484.

7. Snoeck CJ, Marinelli M, Charpentier E, Sausy A, Conzemius T, Losch S and Muller CP (2013) Characterization of newcastle disease viruses in wild and domestic birds in Luxembourg from 2006 to 2008. Applied Environmental Microbiology,79, 639-45.

8. Miller P J and Koch G (2013) Newcastle disease. Diseases of Poultry, 13, 89-138.

9. Nantha Kumar T, Kataria RS, Tiwari AK, Butchaiah G and Kataria JM (2000) Pathotyping of Newcastle disease viruses by RT-PCR and restriction enzyme analysis. Veterinary Research Communications, 24(4), 275-286.

10. Gowthaman V, Ganesan V, Gopala Krishna Murthy TR, Nair S, Yegavinti N, Saraswathy PV, Suresh Kumar G, Udhayavel S, Senthilvel K and Subbiah (2018) Molecular phylogenetics of Newcastle disease viruses isolated from vaccinated flocks during outbreaks in Southern India reveals circulation of a novel sub-genotype. Transboundary and Emerging Diseases, 66(1),363-372.

11. Kumar S, Stecher G, Li M, Knyaz C and Tamura K (2018). MEGA X: molecular evolutionary genetics analysis across computing platforms. Molecular Biology and Evolution, 35(6), 1547-1549.

12. Reed L J and Muench H (1938) A simple method of estimating fifty per cent end points. American Journal of Epidemiology, 27(3), 493-497.

13. Roohani K, Tan SW, Yeap SK, Ideris A, Bejo MH and Omar AR (2015) Characterisation of genotype VII Newcastle disease virus (NDV) isolated from NDV vaccinated chickens, and the efficacy of LaSota and recombinant genotype VII vaccines against challenge with velogenic NDV. J Vet Sci 16, $447-457$.

14. King DJ (1996) Influence of chicken breed on pathogenicity evaluation of velogenic neurotropic Newcastle disease virus isolates from cormorants and turkeys. Avian Disease, 210-217.

15. Alexander DJ, Manvell RJ and Parsons G (2006) Newcastle disease virus (strain Herts 33/56) in tissues and organs of chickens infected experimentally, Avian Pathology, 35(02), 99-101.

16. Kattenbelt JA, Stevens MP and Gould AR (2006) Sequence variation in the Newcastle disease virus genome. Virus research, 116(1-2), 168-184.

17. Ghalyanchi-Langeroudi ARASH, Hosseini H, Madadgar O, Karimi V and Ghafari MM (2011) Sequence analysis of fusion gene of Newcastle disease viruses isolated from ostrich (Struthio camelus) in Iran, Iranian Journal of Virology, 5(3), 12-17.

18. Esmaelizad M, Mayahi V, Pashaei M and Goudarzi H (2016) Identification of novel Newcastle disease virus sub-genotype VII-(j) based on the fusion protein, Archives of Virology, 162, 971-978.

19. Ghodasara P D, Joshi B P, Prajapati K S, Ghodasara DJ, Mathakiya RA, Khorajiya JH and Pandey S (2015) Patho- epidemiological study on Genotype-XIII Newcastle disease virus infection in commercial vaccinated layer farms. Veterinary World, 8(3), 372-381.

20. Zhu J, Hu S, Xu H, Liu J, Zhao Z, Wang X and Liu X (2016) Characterization of virulent Newcastle disease viruses from vaccinated chicken flocks in Eastern China. BMC Veterinary Research, 12(1), 1-9.

21. Jakhesara SJ, Prasad VVSP, Pal JK, Jhala MK, Prajapati KS and Joshi CG (2016) Pathotypic and sequence characterization of Newcastle disease viruses from vaccinated chickens reveals circulation of genotype II, IV and XIII and in India. Transboundary and emerging diseases, 63(5), 523-539.

22. Gowthaman V, Singh SD, Dhama K, Desingu PA, Kumar A, Malik YS and Munir M (2016) Isolation and characterization of genotype XIII Newcastle disease virus from Emu in India, Virus Disease 27(3),315-318.

23. Orynbayev MB, Fereidouni S, Sansyzbai AR, Seidakhmetova BA, Strochkov VM, Nametov AM, Sadikaliyeva SO, Nurgazieva A, Tabynov KK, Rametov NM and Sultankulova KT (2018) Genetic diversity of avian avulavirus1 (Newcastle disease virus genotypes Vlg and VIlb) circulating in wild birds in Kazakhstan. Archives of Virology, 163(7):1949-1954. 
24. Assuncao P, De Ponte Machado M, De la Fe C, Ramírez AS, Rosales RS, Antunes NT, Poveda C and Poveda JB (2007) Prevalence of pathogens in great white pelicans (Pelecanusonocrotalus) from the Western Cape, South Africa, Journal of Applied Animal research, 32, $29-32$.

25. Desingu PA, Singh SD, Dhama K, Karthik K, Vinodh Kumar OR and MalikY S (2016) Phylogenetic analysis of Newcastle Disease virus isolates occurring in India during 1989-2013, Virus Disease, 27(2), 203-206.

26. Kwon H J, Cho S H, Ahn Y J, Seo S H, Choi K S and Kim SJ (2003) Molecular epidemiology of Newcastle disease in Republic of Korea, Veterinary Microbiology, 95(1-2), 39-48.

27. Das M and Kumar S (2017) Evidence of independent evolution of genotype XIII Newcastle disease viruses in India, Archives of Virology, $162(4), 997-1007$.

28. Nath B and Kumar S (2017) Emerging variant of genotype XIII Newcastle disease virus from Northeast India. Acta Tropia, 172, 64-69.

29. Dortmans JC, Koch G, Rottier PJ and Peeters BP (2009) Virulence of pigeon paramyxovirus type 1 does not always correlate with the cleavability of its fusion protein. Journal of General Virology, 90(11), 2746-2750.

30. Desingu P A, Singh S D, Dhama K, Kumar O V, Malik YS and Singh R (2017) Clinicopathological characterization of experimental infection in chickens with sub-genotype VIli Newcastle disease virus isolated from peafowl, Microbial Pathogenesis, 10(5), 8-12.

31. Ferreira H L, Taylor T L, Dimitrov K M, Sabra M, Afonso C L and Suarez DL (2019) Virulent Newcastle disease viruses from chicken origin are more pathogenic and transmissible to chickens than viruses normally maintained in wild birds, Veterinary Microbiology, 235, 25-34.

32. Xu Q, Sun J, Gao M, Zhao S, Liu H, Zhang T, Han Z, Kong X and Liu S (2017) Genetic, antigenic, and pathogenic characteristics of Newcastle disease viruses isolated from geese in China. Journal of Veterinary Diagnostic Investigation, 29(4), 489-498.

33. Warke A, Appleby L and Mundt E (2008) Prevalence of antibodies to different avian paramyxoviruses in commercial poultry in the United States. Avian Diseases, 52 (4): 694-697.

34. Seal, BS, King DJ, Locke DP, Senne DA and Jackwood MW (1998) Phylogenetic relationships among highly virulent Newcastle disease virus isolates obtained from exotic birds and poultry from 1989 to 1996, Journal of Clinical Microbiology, 36: 1141-5.

35. Vijayarani K, Muthusamy S, Tirumurugan KG, Sakthivelan SM and Kumanan K (2010) Pathotyping of a Newcastle disease virus isolated from peacock (Pavo cristatus). Tropical Animal Health and Production, 42(3), 415-419.

36. Garcia CS, Lopez RN, Morales R, Olvera MA, Marquez MA, Merino R, Miller PJ and Afonso CL (2013) Molecular epidemiology of Newcastle disease in Mexico and the potential spillover of viruses from poultry into wild bird species, Applied Environmental Microbiology, 79 (16), $4985-4992$.

37. Dimitrov KM, Ramey AM, Qiu X, Bahl J and Afonso CL (2016) Temporal, geographic, and host distribution of avian paramyxovirus 1 (Newcastle disease virus), Infection, Genetics and Evolution, 39, 22-34.

\section{Tables}

Table 1. Pathogenicity features of the AAvV-1 isolates

\begin{tabular}{llllll} 
Isolate & MDT $(\mathbf{h})$ & ICPI & FPCS & HA titre & HI \\
\hline AAvV/Chicken/ Sklm/2018 & 45 & 1.80 & ${ }^{113} \mathrm{RRKR} \downarrow \mathrm{F}^{117}$ & $2^{6}$ & Positive \\
AAvV/Pelican/ & 48 & 1.85 & ${ }^{113} \mathrm{RRKR} \downarrow \mathrm{F}^{117}$ & $2^{5}$ & Positive \\
Telineelapuram/2018 & & & & &
\end{tabular}

Table 2. Comparision of amino acid substitutions within the functional domains of fusion protein sequence

\begin{tabular}{|c|c|c|c|c|c|c|c|c|c|c|c|c|c|c|c|c|c|c|c|c|}
\hline \multirow{3}{*}{$\begin{array}{l}\text { Virus } \\
\text { strains }\end{array}$} & \multirow{2}{*}{\multicolumn{3}{|c|}{$\begin{array}{l}\text { Fusion peptide } \\
(117-141)\end{array}$}} & \multirow{3}{*}{$\begin{array}{l}\text { HRa } \\
(143- \\
185) \\
145\end{array}$} & \multirow{2}{*}{\multicolumn{2}{|c|}{$\begin{array}{l}\mathrm{HRb} \\
(268-299)\end{array}$}} & & & & \multirow{2}{*}{\multicolumn{4}{|c|}{$\begin{array}{l}\text { HRc } \\
(471-500)\end{array}$}} & \multirow{3}{*}{$\begin{array}{l}\text { HRd } \\
(81- \\
102) \\
82\end{array}$} & \multicolumn{6}{|c|}{ Transmembrane domains } \\
\hline & & & & & & & & & & & & & & & \multicolumn{5}{|c|}{$14-27$} & \multirow{2}{*}{$\begin{array}{l}\mathbf{( 5 1} \\
50\end{array}$} \\
\hline & 117 & 121 & 124 & & 272 & 282 & 288 & 291 & 294 & 479 & 482 & 486 & 494 & & 14 & 16 & 17 & 20 & 22 & \\
\hline LaSota & $\mathrm{L}$ & 1 & G & $\mathrm{K}$ & $\mathrm{N}$ & $\mathrm{L}$ & $\mathrm{T}$ & S & $\mathrm{N}$ & $\mathrm{N}$ & $E$ & $\mathrm{R}$ & $\mathrm{K}$ & $\mathrm{D}$ & M & $\mathrm{T}$ & 1 & $A$ & V & 1 \\
\hline $\mathrm{R}_{2} \mathrm{~B}$ & $\mathrm{~F}$ & - & - & - & - & - & - & - & - & G & - & $S$ & - & - & - & - & $\mathrm{V}$ & - & - & $\mathrm{V}$ \\
\hline $\mathrm{B}_{1}$ & - & - & - & - & - & - & - & - & - & - & - & - & - & - & - & - & - & - & - & - \\
\hline Komarov & $\mathrm{F}$ & - & - & - & - & - & - & - & - & - & - & $S$ & - & - & - & - & V & - & - & - \\
\hline Mukteshwar & $\mathrm{F}$ & - & - & $\mathrm{N}$ & - & - & - & - & - & $\mathrm{D}$ & - & $S$ & $\mathrm{R}$ & E & - & - & - & $\mathrm{T}$ & $A$ & V \\
\hline $\begin{array}{l}\text { AAVV/Chicken/ } \\
\text { SKLM/2018 }\end{array}$ & $\mathrm{F}$ & V & $S$ & $\mathrm{~N}$ & $\mathrm{Y}$ & I & $\mathrm{N}$ & $\mathrm{T}$ & $S$ & $\mathrm{D}$ & $A$ & $S$ & $\mathrm{R}$ & $\mathrm{E}$ & G & 1 & $\mathrm{~T}$ & M & 1 & $A$ \\
\hline $\begin{array}{l}\text { AAVV/Pelican/ } \\
\text { Telineelapuram/ } \\
2018\end{array}$ & $\mathrm{~F}$ & $\mathrm{~V}$ & $S$ & $\mathrm{~N}$ & $\mathrm{Y}$ & I & $\mathrm{N}$ & $\mathrm{T}$ & S & $\mathrm{D}$ & $A$ & $S$ & $\mathrm{R}$ & $E$ & G & I & $\mathrm{T}$ & M & 1 & $A$ \\
\hline
\end{tabular}


-: no change in amino acid compared to that of LaSota

Table 3. Comparision of amino acid substitutions in fusion protein at the hypervariable region and neutralizing epitopes

\begin{tabular}{|c|c|c|c|c|c|c|c|c|c|c|c|c|c|c|c|c|c|c|c|}
\hline \multirow{2}{*}{$\begin{array}{l}\text { Virus } \\
\text { strains }\end{array}$} & \multicolumn{15}{|c|}{ Hypervariable region } & \multicolumn{4}{|c|}{ Neutralizing epitopes } \\
\hline & 4 & 10 & 11 & 13 & 14 & 16 & 17 & 20 & 22 & 25 & 26 & 27 & 28 & 29 & 30 & 31 & 69 & $72,74,75,78,79$ & $157-171$ \\
\hline LaSota & $\mathrm{R}$ & $P$ & A & M & M & $\mathrm{T}$ & I & $A$ & $\mathrm{~V}$ & $\mathrm{C}$ & I & C & $\mathrm{P}$ & $A$ & $\mathrm{~N}$ & $S$ & $\mathrm{~L}$ & DEAKA & SIAATNEAVHEVTI \\
\hline $\mathrm{R}_{2} \mathrm{~B}$ & - & - & $\mathrm{T}$ & - & - & - & $\mathrm{v}$ & - & - & - & - & - & - & - & - & - & - & - & - \\
\hline $\mathrm{B}_{1}$ & - & - & - & - & - & - & - & - & - & - & - & - & - & - & - & - & - & - & - \\
\hline Komarov & - & - & $\mathrm{T}$ & - & - & - & V & - & - & - & - & - & - & - & - & - & - & - & - \\
\hline Mukteshwar & - & - & V & $\mathrm{L}$ & - & - & - & $\mathrm{T}$ & A & $\mathrm{Y}$ & $\mathrm{V}$ & $\mathrm{R}$ & $\mathrm{L}$ & $\mathrm{T}$ & $S$ & - & $M$ & - & - \\
\hline $\begin{array}{l}\text { AAvV/Chicken/ } \\
\text { SKLM-1/2018 }\end{array}$ & K & - & I & $\mathrm{L}$ & G & I & $\mathrm{T}$ & $M$ & I & - & - & - & $\mathrm{L}$ & $\mathrm{T}$ & - & - & I & - & - \\
\hline $\begin{array}{l}\text { AAvV/Pelican/ } \\
\text { Telineelapuram/ } \\
2018\end{array}$ & K & - & I & $\mathrm{L}$ & G & I & $\mathrm{T}$ & $M$ & I & - & - & - & $\mathrm{L}$ & $\mathrm{T}$ & - & - & I & - & - \\
\hline
\end{tabular}

Table 4. Comparision of amino acid substitutions within the functional domains of HN protein

\begin{tabular}{|c|c|c|c|c|c|c|c|c|c|c|c|c|}
\hline \multirow{3}{*}{$\begin{array}{l}\text { Virus } \\
\text { strains }\end{array}$} & \multicolumn{4}{|c|}{ HRa (74-89) } & \multirow{2}{*}{\multicolumn{2}{|c|}{$\mathrm{HRb}$}} & \multicolumn{5}{|c|}{ Neutralizing epitopes } & \multirow{3}{*}{ Figures } \\
\hline & & & & & & & \multirow{2}{*}{$\begin{array}{l}\text { Site } 12 \\
494\end{array}$} & \multicolumn{3}{|c|}{ Site $2 \& 12$ (513-521) } & \multirow{2}{*}{$\begin{array}{l}\text { Site } 2 \\
569\end{array}$} & \\
\hline & 75 & 77 & 81 & 84 & 101 & 102 & & 514 & 519 & 521 & & \\
\hline LaSota & $\mathrm{G}$ & $\mathrm{N}$ & $\mathrm{V}$ & I & $\mathrm{T}$ & $\mathrm{T}$ & G & I & $S$ & $S$ & D & \\
\hline Komarov & - & - & - & - & - & - & - & - & - & - & - & \\
\hline $\mathrm{R} 2 \mathrm{~B}$ & - & - & - & - & $S$ & I & - & - & - & - & - & \\
\hline B1 & - & - & - & - & - & - & - & - & - & - & - & \\
\hline Mukteshwar & - & - & - & - & $\mathrm{S}$ & I & $\mathrm{D}$ & - & - & - & - & \\
\hline AAvV/Chicken/ SKLM-1/2018 & $\mathrm{S}$ & G & I & $\mathrm{V}$ & $\mathrm{S}$ & 1 & $\mathrm{D}$ & V & A & $\mathrm{R}$ & V & \\
\hline AAvV/Pelican/ Telineelapuram/ 2018 & $\mathrm{~S}$ & G & 1 & $\mathrm{~V}$ & S & I & $\mathrm{D}$ & $\mathrm{v}$ & A & $\mathrm{R}$ & V & \\
\hline
\end{tabular}




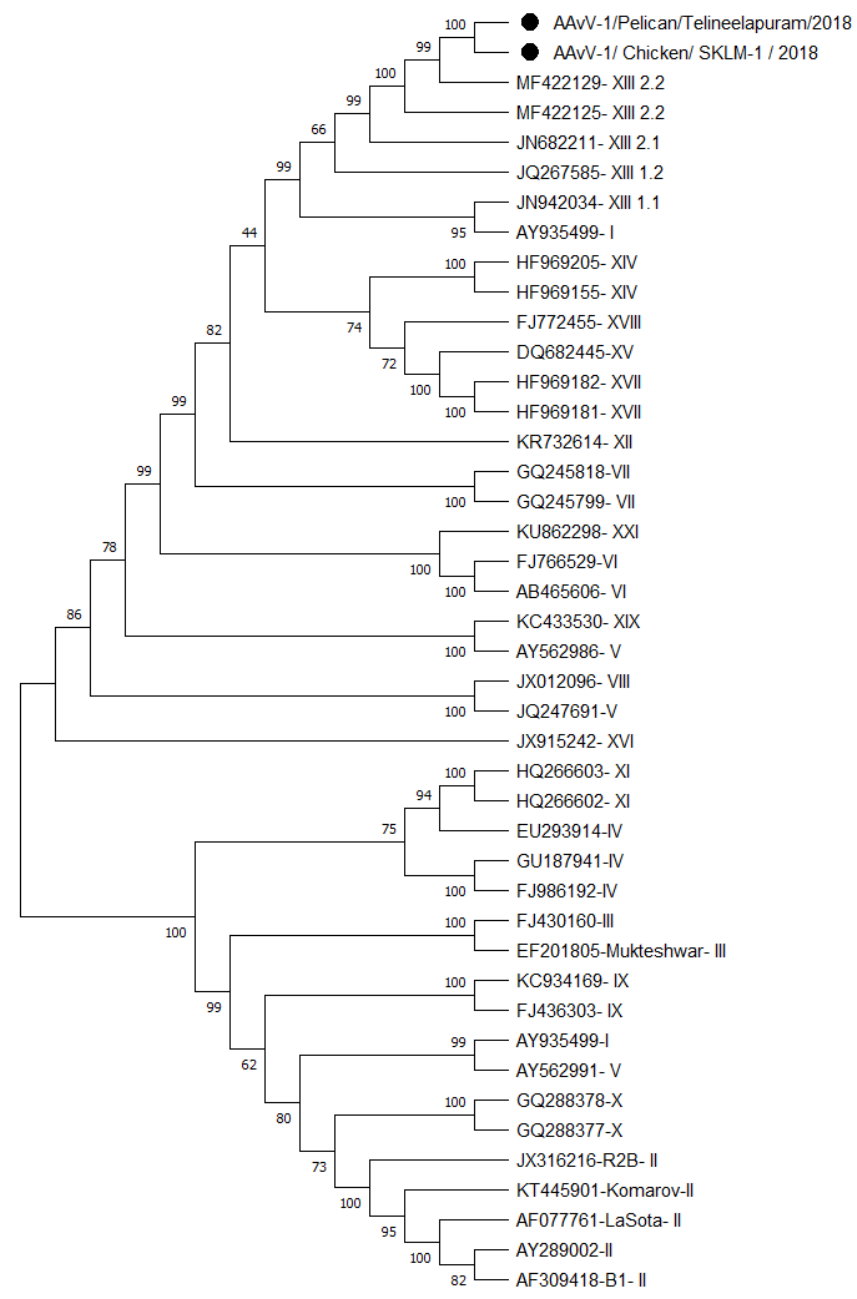

\section{Figure 1}

Evolutionary analysis by Maximum Likelihood method. The evolutionary history was inferred by using the Maximum Likelihood method and General Time Reversible model [1]. The tree with the highest log likelihood (-14950.65) is shown. The percentage of trees in which the associated taxa clustered together is shown next to the branches. Initial tree(s) for the heuristic search were obtained automatically by applying Neighbor-Join and BioNJ algorithms to a matrix of pairwise distances estimated using the Maximum Composite Likelihood (MCL) approach, and then selecting the topology with superior log likelihood value. This analysis involved 43 nucleotide sequences. Codon positions included were 1st+2nd+3rd+Noncoding. There were a total of 1662 positions in the final dataset. Evolutionary analyses were conducted in MEGA X [2]. 


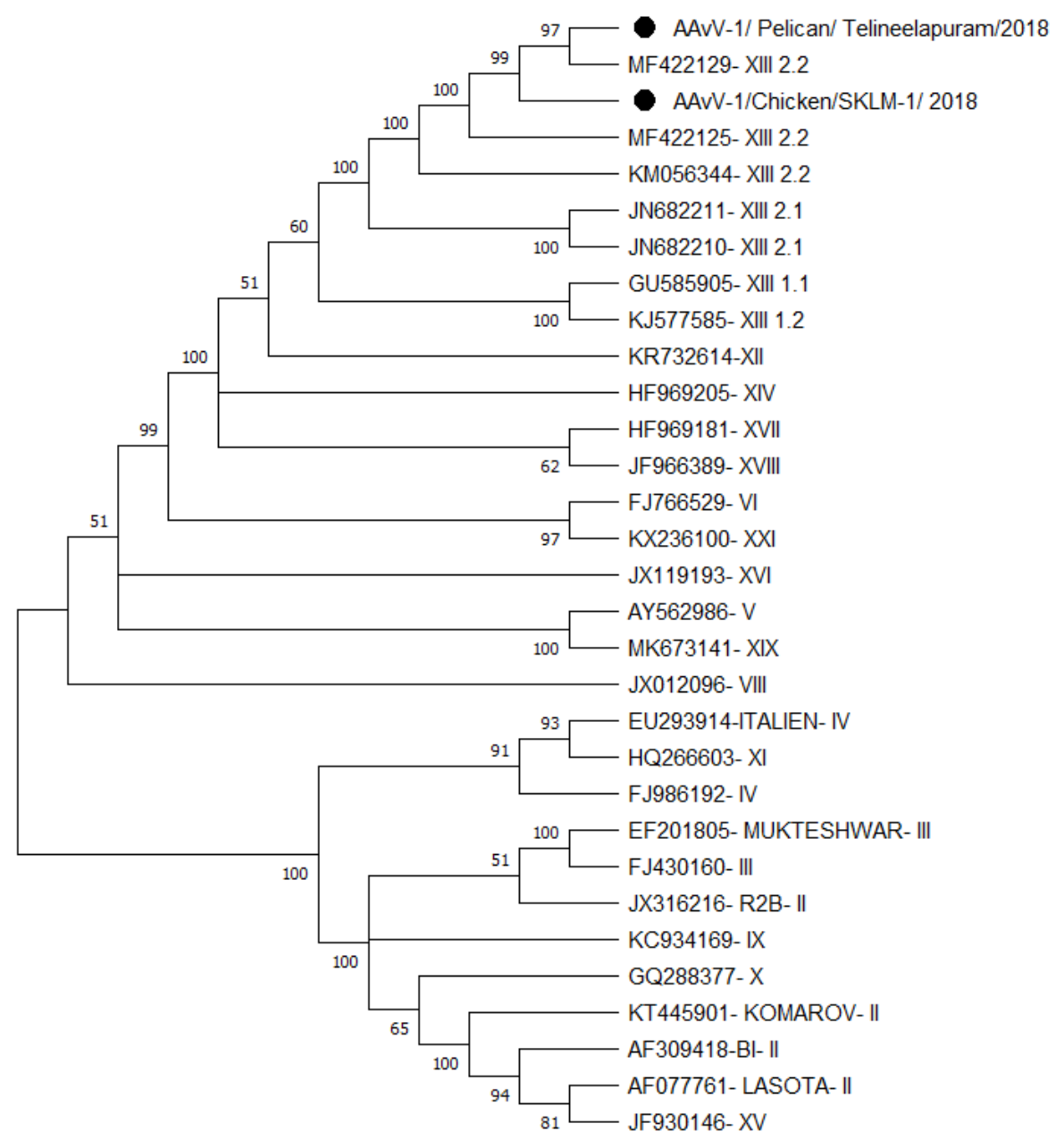

\section{Figure 2}

Evolutionary analysis by Maximum Likelihood method. The evolutionary history was inferred by using the Maximum Likelihood method and General Time Reversible model [1]. The tree with the highest log likelihood (-13516.67) is shown. The percentage of trees in which the associated taxa clustered together is shown next to the branches. Initial tree(s) for the heuristic search were obtained automatically by applying Neighbor-Join and BioNJ algorithms to a matrix of pairwise distances estimated using the Maximum Composite Likelihood (MCL) approach, and then selecting the topology with superior log likelihood value. This analysis involved 31 nucleotide sequences. Codon positions included were 1st+2nd+3rd+Noncoding. There were a total of 1716 positions in the final dataset. Evolutionary analyses were conducted in MEGA X [2].
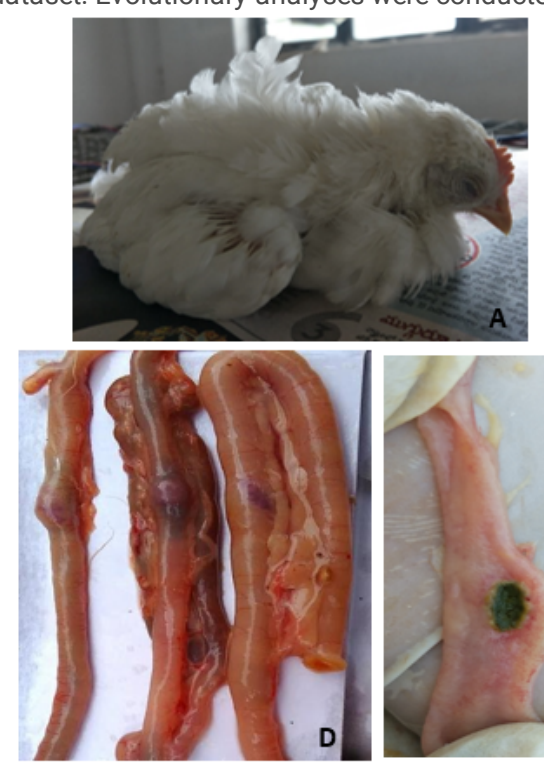
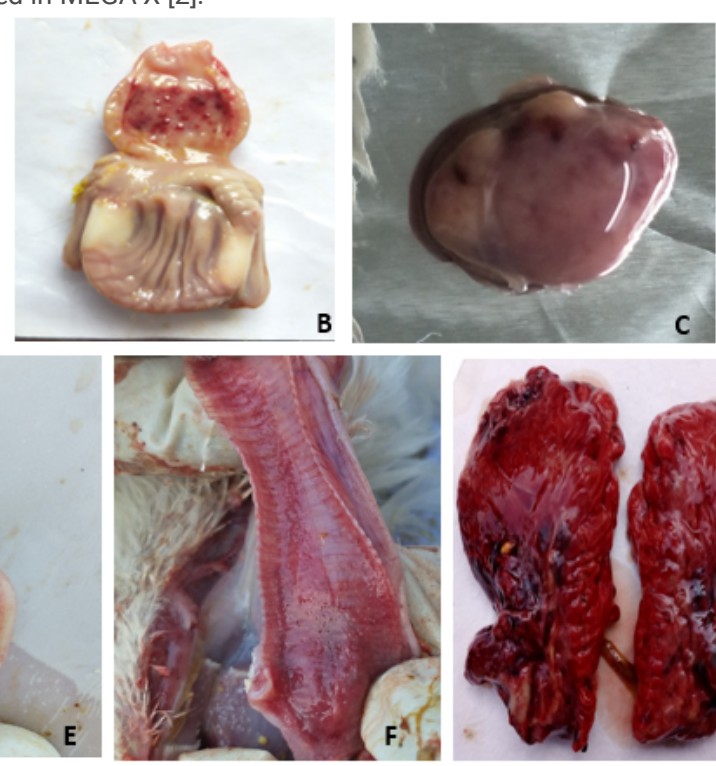

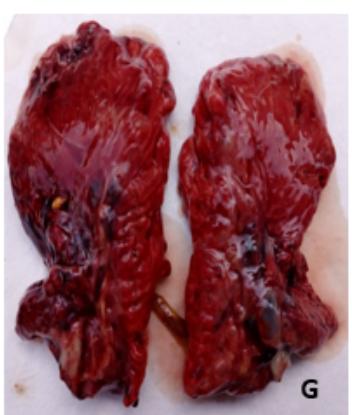


Figure 3

Clinical signs and gross lesions observed after infection of chicks: A. Moribund chick; B. Hemorrhages at the tips of proventricular glands; C. Spleen showing mottling and focal necrotic areas; D \& E. Caecal tonsil necrosis with typical button ulcers; F. Tracheal hemorrhages; G. Hyperemic lungs.
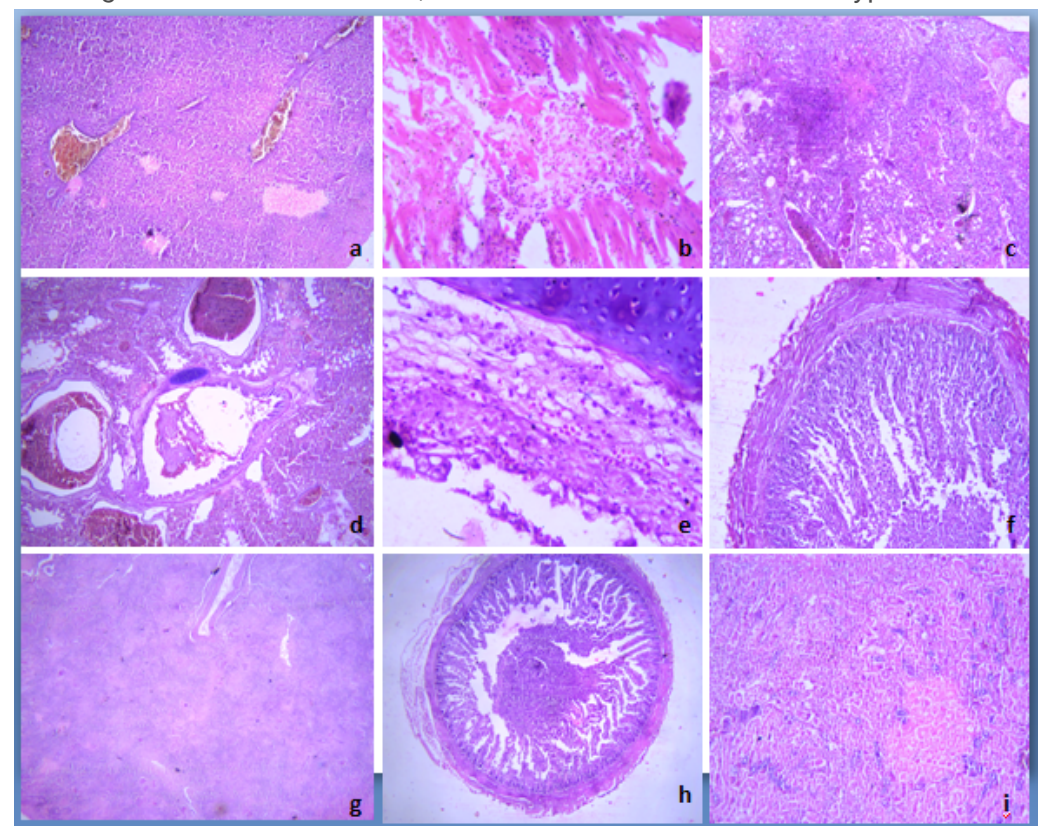

\section{Figure 4}

Histopathological lesions in H\&E stained tissue sections of experimentally infected chicks. a. Liver- Pockets of necrosis and congestion (4X). b. HeartMyocardial degeneration with infiltration of mononuclear cells (40X). c\&d Lung- Hyperplastic bronchiolar epithelium, congestion and exudation in the lumen (4X). e. Trachea- Necrosis of tracheal epithelium, hemorrhage and infiltration of macrophages, lymphocytes, plasma cells and fibrin (40X). f. IntestineNecrosis of intestinal villi and denudation into the lumen (10X). g. Spleen- Lymphoid depletion and diffuse necrosis (4X). h. Jejunum- Denudation of epithelium into lumen (4X). i. Kidney- Severe tubular necrosis (10X).

\section{Supplementary Files}

This is a list of supplementary files associated with this preprint. Click to download.

- Supplementarymaterial.docx 